\title{
I FIORETTI DE SAN FRANCESCO COMO INSTRUMENTOS DE COMUNICAÇÃO DO CRISTIANISMO NO TRECENTO ITALIANO: INDÍCIOS DE UM CONTEXTO CULTURAL
}

\author{
I Fioretti de San Francesco as communication \\ tools of Christianity in the Italian Trecento: \\ evidence from a cultural context
}

\section{Luís Henrique Marques*}

\section{RESUMO}

Este trabalho tem como objetivo apresentar uma leitura crítica da obra I Fioretti de San Francesco, de autor desconhecido, vista aqui como instrumento de comunicação do cristianismo e, mais precisamente, do Movimento Franciscano para a causa da evangelização e, sobretudo, como meio de representação cultural (especialmente, da religiosidade) do Trecento italiano, período inicial do Renascimento, época em que foi produzida e publicada essa obra. Para tanto, fundamentalmente, a leitura de I Fioretti é feita no confronto com alguns argumentos importantes utilizados por Jacob Burckbardt na sua análise sobre o Renascimento italiano. A conclusão central deste estudo é que I Fioretti, ao resgatar a experiência cristã de Francisco e de alguns de seus seguidores mais fiéis, ainda que não de forma prioritária, quer evidenciar valores morais e culturais defendidos pela Igreja ao longo da Idade Média e que passaram a ser confrontados com o advento do Renascimento e de sua visão humanística anticlerical.

Palavras-chave: I Fioretti de San Francesco. Franciscanismo e Comunicação. Franciscanismo e Trecento.

* Jornalista e historiador; docente de Jornalismo da UNIP; tutor de História do Centro Universitário Claretiano; mestre em Comunicação pela UNESP-Bauru; doutor em História pela UNESP-Assis. <http://profluismarques.blog.terra.com.br/>.

\begin{tabular}{|l|l|l|l|l|l|}
\hline Teocomunicação & Porto Alegre & v. 44 & n. 1 & p. 122-137 & jan.-abr. 2014 \\
\hline
\end{tabular}




\begin{abstract}
This article aiming to present a critical reading of the I Fioretti de San Francesco work, from unknown author, here seen as communication tool of Christianity and more especifically of the Franciscan Movement for the evangelization cause and, above all, as a mean of cultural representation (especially of the religiosity) of the italian Trecento, initial period of Renaissance, time which this work was produced and published. For this, fundamentally, the reading of I Fioretti is made in the confrontation with some important arguments used by Jacob Burckbardt in his analysis about the italian Renaissance. The central conclusion of this study is that I Fioretti, when rescue the Christian experience of Francesco and some of his more faithful following, even if not in a priority way, wants to evidence moral and cultural values defended by Church during the Medium Age and started be confronted since the Renaissance advent and its anticlerical humanistic vision.
\end{abstract}

Keywords: I Fioretti de San Francesco. Franciscanism and Comunication. Franciscanism and Trecento.

\title{
Introdução
}

O cristianismo nasceu com a vocação para comunicar. A própria expressão "evangelho" (originária do grego cujo significado é "boa nova, boa notícia") já revela uma vocação cristã ao anúncio da mensagem do Cristo. "Ide pelo mundo e pregai o Evangelho a todas as gentes", disse Jesus (Evangelho de Mateus, capítulo 16, versículo 15). De fato, o cristianismo, na sua gênese, já possui a vocação à propagação:

O acontecimento de Cristo, envolvendo a vida do homem, gerou um fluxo humano ininterrupto: o povo cristão. Pertencer ao povo de Deus (que no judaísmo tinha fundamento étnico, ou seja, erase hebreu por nascimento) caracteriza-se de modo novo como consciência de ser membros, através do batismo, do Corpo místico de Cristo, Seu prolongamento na história. É a certeza desta Presença que conduz os primeiros doze pelas estradas de todo o Império (romano), a levar o inconcebível anúncio: 'O Verbo se fez carne e veio habitar entre nós' (Evangelho de João, capítulo 1, versículo 14). É elemento fundamental da consciência dos primeiros cristãos considerarem-se depositários de uma resposta global e definitiva à espera de salvação de cada homem: 'Porque Cristo apareceu como redentor da humanidade inteira, por isso também o Seu corpo, por essência, tende a incluir a humanidade inteira' (K. Adam). 
Representam bem esta consciência as viagens apostólicas da primeira evangelização (...) Assiste-se, assim, à formação rapidíssima de comunidades cristãs em todo o mundo então conhecido: oikoumene (terra habitada)." (MARQUES, 1999 apud CENTRO CULTURAL XII DE OUTUBRO, 1998).

Rompendo assim, o fundamento étnico do judaísmo, do qual nascera, o cristianismo torna-se uma "religião de comunicação e não de segredos” (MARIZ, 1998 apud MARQUES, 1999). É uma religião que, "ao contrário de religiões onde há ordens secretas e mistérios somente revelados aos iniciados, onde os fiéis devem ser discretos", "quer pregar, se expandir e aparecer" (MARIZ, ibid). Para Marcello Azevedo, "nenhuma outra religião traduz assim esta consciência existencial de sua universalidade, embora seja profundo em muitas o calado humano supertemporal de sua expressão religiosa e até mesmo a ampla difusão territorial de sua presença" (AZEVEDO, 1991 apud MARQUES, 1999).

Considerado um dos mais significativos e radicais da história da Igreja Católica, o Movimento Franciscano - por sua inspiração tipicamente cristã e evidente catolicidade (a submissão de Francisco de Assis à Santa Sé sempre foi clara), assumiu inteiramente esse empenho de comunicar (ou de pregar) a Boa Nova, missão confiada pelo próprio Cristo a todos os seus seguidores, sob a perspectiva (carisma) da pobreza evangélica.

Sobre a ação missionária de Francisco de Assis, afirma Durval de Paula (p. 11):

Tinha Francisco de Assis o desejo que a luta se desse por meio da palavra e pelo exemplo, o que, segundo ele, realmente traria à conversão os infiéis e hereges; torna a linguagem o mais próximo possível das pessoas que o seguiam, dos pobres, da gente comum das vilas e idades por onde passava.

As Sagradas Escrituras sempre foram, por excelência, o principal instrumento de comunicação da mensagem cristã utilizada pelos seguidores de Francisco de Assis, a exemplo do que acontecera e acontece com diferentes segmentos do cristianismo. No entanto, o próprio Movimento Franciscano, ao longo do tempo, foi responsável pela criação de uma profícua literatura religiosa que serviu de suporte a esse trabalho missionário. 
Entre essas obras, encontra-se I Fioretti de San Francesco, uma coletânea de cinquenta e três narrativas produzidas durante o Trecento italiano (por volta de 1370 a 1390) que ilustram episódios da vida do santo de Assis, de seus companheiros (os primeiros trinta e oito fioretti), da Ordem Franciscana e de alguns irmãos spirituali dessa congregação, da região italiana das Marcas (os últimos treze fioretti). "Este livro contém alguns Fioretti", diz o autor na abertura da obra, "milagres e exemplos devotos do glorioso pobrezinho de Cristo, monsenhor S. Francisco, e de alguns santos seus companheiros". Além disso,

... os fioretti XXXIX e XL são dedicados a Santo Antônio de Pádua. Contam um período de mais ou menos cem anos - da conversão de Bernardo Quintavalle, primeiro discípulo de Francisco (1209) aos acontecimentos da vida de Giovanni della Vernia (1259-1322), que entrou para a Ordem em 1272. Originalmente, o texto possui cinquenta e dois capítulos, mas as edições mais recentes do século $\mathrm{XV}$ já trazem o primeiro capítulo dividido em dois (BALANCIN, 2008, p. 14).

\section{Metodologia}

Para construir ao menos alguns dos elementos marcantes do contexto histórico do início do Renascimento italiano, nos serviremos da obra de Jacob Burckhardt - A cultura do Renascimento na Itália: um ensaio - da qual extraímos alguns argumentos que podem ser aplicados na análise de I Fioretti. Assim, de posse de tais argumentos, esperamos apresentar, com alguma coerência, representações desse momento cultural italiano presentes na obra franciscana, a despeito desta ter objetivos hagiográficos (e não histórico-culturais), além de demonstrar como a obra foi pensada como instrumento de comunicação das verdades da fé cristã conforme assinalamos no início deste texto.

É importante fazer ainda uma ressalva quanto ao uso da obra de Burckhardt: embora ela tenha a pretensão de abarcar todo o Renascimento italiano, procuramos nos valer de argumentos que, segundo nossa compreensão, se encaixam mais com esse período inicial - o Trecento e cujo confronto com I Fioretti nos viabiliza uma leitura coerente. Nesse último caso, privilegiamos a leitura sobre o contexto cultural religioso (e espiritual) que o autor suíço realiza. 
Por fim, vale salientar também que, embora se reporte a fatos (ou supostos fatos) passados e, desse modo, revele uma intenção de registro para as novas gerações a respeito da experiência original de Francisco e de alguns dos seus seguidores, o autor de I Fioretti escreve, sobretudo, sob influência e para o contexto cultural do seu tempo. Isso implica considerar que o fato de privilegiar esse ou aquele argumento, realizar esse ou aquele comentário, é possível levar em conta as intenções do narrador em se dirigir especialmente para os interlocutores do seu tempo e meio ambiente.

Com efeito, como mostraremos a seguir, mesmo se indiretamente, o autor de I Fioretti parece escrever inspirado, motivado ou influenciado pelo período de transição cultural que é o Trecento, isto é, de uma visão plenamente teocêntrica para uma visão antropocêntrica, ainda que esta, no início do Renascimento, não negue a fé cristã, mas deseje adaptar a experiência religiosa a uma perspectiva mais humanista pela qual o ser humano, por vontade de Deus, é o centro da história. Para a religiosidade franciscana daquele momento - a julgar pelo teor dos relatos de I Fioretti - essa perspectiva parece soar herética ou, pelo menos, inadequada, uma vez que o conceito de pobreza evangélica (cerne do carisma de Francisco de Assis) implica a negação do ser humano e sua total subserviência a Deus. O autor de I Fioretti, desse modo, parece ir na contramão dessa visão antropocêntrica, ainda que o texto não faça uma referência explícita à visão humanista, inclusive porque não demonstra a pretensão de promover qualquer debate filosófico. Trata-se, simplesmente, da proclamação daquilo que o autor considera verdades de fé, conforme a experiência de Francisco de Assis e de alguns de seus seguidores mais importantes.

\section{Franciscanismo}

Já no seu início no século 13, "a postura missionária do grupo de franciscanos foi levada aos limites do mundo cristão, proporcionando uma aventura para além" (SANTOS, 2005, p. 33), fazendo com que o próprio Francisco de Assis empreendesse uma viagem ao Egito na expectativa de converter o sultão, assim como os primeiros franciscanos foram encorajados a pregar o Evangelho aos muçulmanos daquela época. Esse empreendimento, especificamente, não teve sucesso, mas é fato que o franciscanismo seguiu seu trabalho missionário por outras regiões do mundo. 
Ao introduzir a tradução para o português do Brasil da obra Legenda Aurea, do dominicano Jacopo de Varezze, Hilário Franco Júnior, referindo-se às Ordens Mendicantes, com destaque para dominicanos e franciscanos, afirma que estas "atuavam no meio dos leigos, ao contrário dos monges tradicionais, enclausurados na segurança e riqueza dos mosteiros" (in: VAREZZE, 2003, p. 13).

Além disso, dentro de suas estratégias de comunicação, os mendicantes utilizavam mais das línguas vulgares que do latim e recorriam mais a narrativas de fundo folclórico do que a textos teológicos, o que os aproxima ainda mais da maior parte da população simples e analfabeta. "Não que lhes faltasse o saber erudito: na maior parte das nascentes universidades do século XIII, os grandes teólogos eram franciscanos (por exemplo, Boaventura e Roger Bacon) e dominicanos (caso de Alberto Magno e Tomás de Aquino)", esclarece Franco Júnior (in: VAREZZE, ibid, p. 13).

Jean Claude Schmitt (1999, p. 154) considera as Ordens Mendicantes uma verdadeira "máquina de pregação". A análise desse autor confirma essa postura, sobretudo de dominicanos e franciscanos, de utilizar recursos literários que as tornem populares. Um desses recursos é que os "heróis" de suas historietas, bastante utilizadas em suas pregações, são pessoas de "todas as categorias sociais", de "todos os grupos de idade" e de ambos os sexos.

Já desde o século XIII, sob influência dessas ordens, a pregação passa "por profundas transformações quantitativas e qualitativas" (SCHIMITT, 1999, p. 144). Nesse sentido, "a retórica do sermão tornase sistemática para alcançar maior eficácia: ela impõe um plano estrito, divisões invariáveis e a trilogia obrigatória de seus argumentos: as 'autoridades' (auctoritates) tiradas da Bíblia ou dos autores cristãos enunciam todas as facetas (ainda que contraditórias) da tradição autorizada" (SCHIMITT, ibid, p. 144).

\section{Sobre I Fioretti}

Embora não se trate precisamente de uma obra catequética, partimos do pressuposto de que I Fioretti de San Francesco tem como objetivo último a evangelização a partir do exemplo, ${ }^{1}$ do testemunho

O recurso do exemplo foi, desde os séculos anteriores ao Trecento, um recurso bastante utilizado pelos pregadores cristãos na tentativa de persuadir seus fiéis. Segundo SCHIMITT (1999, p. 144), "os 'exemplos' (exempla) ilustram, sob a forma de relatos breves e concretos, fábulas ou historietas, as vantagens, para o cristão, de uma justa conduta”. 
de vida de Francisco e de seus companheiros, inspirado no seguimento radical de Cristo, sob o carisma da pobreza evangélica. Nesse sentido, I Fioretti - cuja autoria real é desconhecida, ${ }^{2}$ o que significa que é equivocada atribuí-la ao próprio Francisco - se assemelha às hagiografias. A propósito dos textos hagiográficos,

Maria Lúcia Andrade (ibid, p. 53) explica que 'a literatura hagiográfica cristã teve início ainda na Igreja Primitiva quando, a partir de documentos oficiais romanos ou de relatos de testemunhas oculares, eram registrados os suplícios dos mártires'. Esse estilo literário, contudo, 'desenvolveu-se e consolidou-se somente a partir da Idade Média, com a expressão do cristianismo e a difusão do culto aos santos', escreve a pesquisadora. Ela chama a atenção para o fato de que, ao longo da Idade Média, 'os textos hagiográficos não só apresentam diferentes formas, como também incorporam concepções diferenciadas de santidade' (p. 53), conforme demonstrado no primeiro item deste capítulo (MARQUES, 2009, p. 121).

Para além de seu propósito explicitamente religioso e quase biográfico (ou melhor, hagiográfico), I Fioretti é valioso documento histórico que retrata um período culturalmente marcante do Ocidente medieval. De fato, o chamado Trecento (século XIV) corresponde à fase inicial da elaboração renascentista, ainda fortemente marcada por elementos medievais (por essa razão, chamada por alguns estudiosos de Pré-Renascimento), entre os quais um "frescor do franciscanismo" (PEREIRA, 2008, p. 34).

O Trecento herdou um período de profundas transformações materiais e culturais que atingiu o Ocidente medieval nos séculos XII e XIII. Uma maior produtividade agrícola e artesanal, o progresso comercial e intensa urbanização, o avanço das línguas vernáculas, o nascimento das universidades e o desenvolvimento da filosofia escolástica estão entre essas transformações.

No campo religioso, acontece justamente o surgimento das Ordens Mendicantes que refletem, segundo Hilário Franco Júnior (in: VAREZZE, 2003, p. 13), a busca de uma religiosidade de sentimento

2 Ainda que o autor de I Fioretti não seja conhecido, em alguns trechos da obra, ele marca presença e revela sua importância, como acontece no término do último capítulo: "E ele, porque confiava muito em mim, narrou-me tudo por ordem." 
"menos formalista e mais interiorizado, menos preocupado com as aparências do que com as intenções". Por sua prática despojada, humilde, de apego à natureza, de intensa pregação e repressão às heresias, as Ordens Mendicantes atendiam "melhor que as velhas ordens monásticas as novas necessidades sociais e espirituais" (FRANCO JÚNIOR, in: VAREZZE, ibid, p. 13). E foi justamente a Itália o epicentro dessas transformações.

Algumas das narrativas presentes em I Fioretti, a propósito, não se limitam à experiência espiritual de Francisco e de seus primeiros seguidores, mas refletem um contexto religioso mais amplo. De fato,

Em suas narrativas, I Fioretti expõem as polêmicas da Ordem Franciscana - vida ativa e contemplativa (cf. Capítulo XVI); franciscanos e dominicanos (cf. Capítulo XVIII); as relações com Luís IX da França (cf. Capítulo XXXIV); a excomunhão de frate Elia (cf. Capítulo XXXVIII); a deposição de Giovanni da Parma por aderir às doutrinas de Joaquim da Fiore (cf. Capítulo XLVIII) e outras (BALANCIN, 2008, p. 15).

Numa análise geral da obra, é possível perceber alguns focos importantes, do ponto de visto religioso e espiritual, aos quais seu autor se dedicou. De maneira geral, eles têm relação direta com o ideal de Francisco de Assis e da revisão do cristianismo que acabou por promover. São perspectivas recorrentes em I Fioretti: o aprendizado e o exercício da humildade mediante a contínua experiência da humilhação - fruto da perseguição por causa de Cristo -, da dor e da pobreza (desapego dos bens materiais e espirituais) como método para cumprir a vontade de Deus e consequente valorização da Providência Divina; assumir para si o sacrifício de Cristo; observância da santa obediência (aos superiores, representantes de Deus ou diretamente a Maria ou a Cristo); frequentes aparições ou visões celestiais e iluminações de inspiração divina e uma paixão intensa por Cristo e pelas coisas de Deus, a ponto de experimentar sensações tipicamente humanas (como o sabor e o odor) como expressões dessa mesma paixão. Essas perspectivas ou experiências permanecem estreitamente ligadas entre si nos relatos dessa obra.

Há exemplo de outros textos de caráter hagiográfico, I Fioretti narra uma série de eventos que, por suas características, são reproduções fiéis de fatos bíblicos, especialmente aqueles encontrados no Novo Testamento. Não é para menos: a experiência de Francisco de Assis e 
de seus seguidores mais fiéis e devotados à causa do Evangelho deve ser uma imitação perfeita da vida de Cristo. “(...) devemos considerar que o glorioso monsenhor S. Francisco, em todos os atos de sua vida, foi conforme a Cristo bendito", escreve o autor de I Fioretti já na abertura do Capítulo 1 da obra.

Com efeito, também a título de exemplo, no Capítulo 19, o autor conta que Francisco evita a multidão que o assedia, assim como é protagonista na transformação do vinho em bebida de ótima qualidade, semelhantemente como acontecera com Cristo, conforme a narrativa evangélica. Francisco faz jejum durante 40 dias e 40 noites, expulsa demônios (Capítulo 7) e escolhe seus doze seguidores diretos e os envia em pares a pregar (Capítulo 13).

Os exemplos nesse sentido abundam ao longo da obra; porém, não nos deteremos neles, uma vez que, aqui, este não é o nosso objetivo central nem estes representam uma contribuição essencial ao propósito deste estudo. Ainda assim, apenas para concluir, esse argumento, reproduzimos no Capítulo 1 um trecho que demonstra ainda mais explicitamente a necessidade do autor em comparar os frades protagonistas dos seus relatos a figuras bíblicas. Diz ele:

(...) um deles foi arrebatado até ao terceiro céu como São Paulo; e este foi Frei Frígio; outro deles, isto é, Frei Filipe Longo, foi tocado nos lábios por um anjo com um carvão em brasa, como o profeta Isaías; outro ainda, chamado Frei Silvestre, falava com Deus como um amigo com outro, do mesmo modo que Moisés; um voava, por sutileza de intelecto, até à luz da divina sapiência, como a águia, isto é, João Evangelista, e este foi Frei Bernardo, o humildíssimo, que profundissimamente interpretava a Santa Escritura (...)

Uma vez que nossa proposta não é fazer uma leitura de I Fioretti devocional nem apenas centrada na figura de Francisco e de seus seguidores e nem mesmo no início do seu movimento, sua análise exige não só o confronto da obra com elementos do contexto histórico em que foi produzida (o Trecento italiano) para compreendê-la como reflexo desse mesmo contexto, quanto permite/reclama o uso de um instrumento teórico-metodológico que possibilite uma leitura - mesmo se apenas preliminar - mais aprofundada do seu uso como instrumento de comunicação/evangelização segundo a perspectiva do franciscanismo, conforme propomos aqui. 


\section{Fioretti e o Trecento italiano}

Como assinalamos anteriormente, por sua proximidade temporal com a Idade Média, o início do Renascimento ainda traz bastante viva a influência do pensamento religioso na orientação dos valores morais e culturais. No entanto, é também desde esse período que cresce, aos poucos, a contestação à supremacia intelectual da Igreja, bem como há uma retomada do humanismo nos moldes da Antiguidade Clássica. Segundo Burckhardt (2009, p. 153), "uma nova cultura contrapõese àquela da Idade Média, àquela cultura, em essência, sempre eclesiástica e cultivada por eclesiásticos; uma nova cultura que se apega predominantemente àquilo que se encontra para além da Idade Média”.

É importante salientar que o Trecento, especificamente, é um período de transição entre uma tradição cultural milenar, marcada por uma visão teocêntrica (Idade Média) e uma nova visão, marcadamente humanista ou antropocêntrica. No entanto e em síntese - uma vez que o espaço não nos permite detalhar essa questão, o que também, de algum modo, estaria muito além de nossas pretensões com este estudo - esse período não implica o rompimento total com a visão cristã e eclesial. Com efeito, segundo Pereira e Torelli (2010, p. 24), o Renascimento, especificamente nessa sua fase inicial, aposta na visão humanista sem, contudo, negar a Deus. Pelo contrário, a pretensão dos primeiros - por assim dizer - renascentistas é reinterpretar a Bíblia à luz dos estudos clássicos antigos.

Nesse sentido, a ciência é vista como uma forma de atingir a verdade e, portanto, uma maneira de se chegar a Deus, o que implica considerar que o estudo fortaleceria a fé e não a negaria. A visão antropocêntrica que ganha força nesse período passa a trabalhar com a especulação em torno do ser humano e de suas capacidades físicas e espirituais, perspectiva, a propósito, bastante valorizada pela Escolástica, já no século XIII. Desse modo, "os humanistas consideravam o homem a criatura divina mais importante, e, assim, tudo que fosse feito por essa criatura em busca do engrandecimento era também considerado algo divino", afirmam Pereira e Torelli (ibid, p. 24) para que, dessa forma, "o humanismo (...) é uma expressão cultural típica da transição da Idade Média para a Moderna" (PEREIRA; TORELLI, ibid, p., 24)

De qualquer modo, essa mudança ou adaptação à visão humanista não é prontamente aceita por toda a cristandade. Por essa razão, no sentido de resistência a essa transformação cultural, grande parte 
do clero (religioso e secular) produz a defesa da cosmovisão cristã, partindo para o ataque de tudo quanto consideravam pagão e imoral por deslocar a centralidade da tradicional visão cristã em Deus para uma atenção mais direta ao ser humano. Entre os que estiveram na linha de frente desse empreendimento, estavam os frades mendicantes, salienta Burckhardt (Ibid, p. 158). Uma condição, portanto, para o sucesso desse empreendimento é - como sempre o fora - o serviço e obediência à Igreja. De fato, o autor de I Fioretti salienta - após narrar que Francisco pregara em reunião de seus confrades (o chamado Capítulo Geral da Ordem), afirma, no Capítulo 18: "E sobre estas palavras, pregando devotíssimamente, confortava e induzia os frades à obediência da santa madre Igreja (...)". ${ }^{3}$

Outra condição para conseguir a manutenção da fé do povo em Cristo e na sua Igreja é o já comentado uso da estratégia da pregação da qual muitos franciscanos se notabilizaram. "Ó Frei Masseo, todos estes teus companheiros têm a graça da contemplação e da oração, mas tu possuis a graça da pregação da palavra de Deus, para satisfazer o povo" (Capítulo 12 de I Fioretti). Porém, para além do dom da pregação em si, este recurso ganha ainda mais força quando associa a um ato milagroso. É o que acontece, por exemplo, quando Antônio de Pádua prega ao papa e aos cardeais e cada um o compreende na própria língua (Capítulo 39) e Francisco prega às aves (Capítulo 49).

$\mathrm{O}$ fato é que o propósito do sermão era sensibilizar as consciências. "Os sermões tratam de questões morais; não apresentam abstrações, mas um punhado de aplicações específicas e se apoiam numa personalidade sagrada e ascética, à qual, então, a fantasia, estimulada, agrega o milagre, mesmo contra a vontade do pregador", afirma Burckhardt (Ibid, p. 337). $\mathrm{O}$ autor explica ainda que, nesse caso, o argumento mais poderoso era a ameaça do purgatório ou do inferno. "A ofensa a Cristo e aos santos tem suas consequências nesta vida. Só assim podia-se mover o indivíduo aferrado à paixão, aos juramentos de vingança e ao crime à expiação e ao arrependimento", claramente o objetivo principal do sermão, completa Burckhardt.

Aliás, aqueles eram tempos difíceis, conturbados. "Com frequência, a crua e atrevida insolência toma o lugar da espiritualidade,

\footnotetext{
3 Semelhante performance é atribuída ao Frei Filipe, no Capítulo 45: "Sobe ao púlpito Frei Filipe para pregar e prega devotadissimamente, não com palavras de sapiência humana, mas em virtude do espírito de Cristo, anunciando o reino da vida eterna".
} 
assumindo a forma da trapaça grosseira, da blasfêmia e da obscenidade" (BURCKHARDT, ibid, p. 126) E mais: "Na fantasia, que domina esse povo mais do que qualquer outro, revela-se, pois, uma causa geral do fato de toda paixão tornar-se, em seu curso, extremamente violenta e, conforme as circunstâncias, criminosa nos meios de que se vale" (BURCKHARDT, ibid, p. 332).

No Capítulo 27, além de converter três ladrões homicidas, Francisco vê, no inferno, marido e mulher que estão pagando o pecado de ter falsificado trigo e aveia no tempo de grande fome, relatos que parecem corroborar com essa análise de Burckhardt.

Há alguns outros exemplos disponibilizados por I Fioretti. No capítulo 20, encontramos: "Um jovem muito nobre e delicado veio para a Ordem de S. Francisco, o qual, depois de alguns dias, por instigação do demônio, começou a ter tal abominação ao hábito que vestia, que lhe parecia trazer um saco vilíssimo; tinha horror às mangas, abominava o capuz e o comprimento e a grandeza lhe pareciam carga insuportável".

Outro exemplo extraído de I Fioretti parece atender a exigência de pacificação de um contexto marcado por disputas e violência, como foi boa parte do Renascimento italiano. ${ }^{4}$ Diz o texto no Capítulo 11:

Ao se aproximarem de Siena, os habitantes da cidade souberam da chegada do santo e vieram-lhe ao encontro e, por devoção, o levaram, mais o companheiro, ao bispado, de modo que eles não trocaram o solo com os pés. Naquela hora, alguns homens de Siena combatiam entre si e dois já haviam morrido. Chegando-se a eles, S. Francisco pregou-lhes tão devotamente e tão santamente que os reduziu a todos à paz e grande união, juntando-os em concórdia.

Num período de grandes paixões humanas como foi o Trecento, a paixão por Cristo (sentida no corpo e na alma) se revela como a bandeira levantada pela Igreja e, especialmente, por Ordens mendicantes como a dos franciscanos, para recompor a ordem estabelecida na Idade Média. No Capítulo 49, o autor de I Fioretti revive cena em que Madalena chora aos pés de Cristo para descrever a paixão com que Frei João resolveu seguir a Cristo:

\footnotetext{
4 A pregação em favor da reconciliação entre pessoas, famílias, grupos e cidades tornouse, com efeito, uma das prioridades de monges devotos e santos, “(...) mas se lograram reduzir o número de vendette já em curso, isso foi tudo o que conseguiram: dificilmente terão impedido o surgimento de novas" (BURCKHARDT, ibid, p. 315).
} 
E Cristo ainda se parte e faz como a mãe ao filho quando o deixa gritar pelo peito e faz que venha atrás dela chorando a fim de que ele mame com mais vontade. Pelo que Frei João com mais fervor ainda e desejo seguiu a Cristo, e chegando que foi a ele, Cristo bendito voltou-se e olhou-o com o semblante alegre e gracioso, e abrindo os seus santíssimos e misericordiosos braços, abraçouse dulcissimamente; e naquele abrir de braços viu Frei João sair do sacratíssimo peito do Salvador raios de luz esplendentes, os quais iluminavam toda a floresta como também a ele na alma e no corpo.

Mas também a própria família franciscana foi alvo dessas paixões, o que obrigou, segundo o relato de I Fioretti, a enfrentar situações, por vezes, embaraçosas. É o caso, por exemplo, em que é pedido ao Frei Conrado de Offida de admoestar um jovem frade que causa de perturbações no convento de Offida:

Pelo que Frei Conrado, por compaixão daquele jovem e pelos pedidos dos frades, chamou à parte o dito jovem e com fervor de caridade lhe disse tão eficazes e devotas palavras de admoestação que, com a operação divina, graça a ele, subitamente se mudou de moço em velho de costumes e tão obediente e benigno e solícito e devoto, e ainda tão pacífico e serviçal, e tão cuidadoso para com todas as coisas de virtude que, como primeiramente toda a família vivia perturbada por ele, assim depois todos estavam contentes e consolados e grandemente o amavam (I FIORETTI, Capítulo 43).

Mas nem todos os frades deixam de sucumbir às paixões. Com efeito, o narrador de I Fioretti relata uma visão que tivera Frei Leão de frades que sofriam ao serem arrebatados para o fundo de um rio impetuoso por conta da sua infidelidade à causa de Cristo (Capítulo 36). "Vendo isso, Frei Leão tinha deles grande compaixão", afirma o texto. $\mathrm{O}$ autor refere-se à compaixão que sentira Frei Leão ao ver os frades infiéis ao cristianismo se afogarem no rio (uma evidente alegoria ao inferno) por conta da má conduta que aqueles tiveram em vida. Podemos relacionar essa passagem com que afirma Burckhardt (2009, p. 332) a respeito das tapeações e explorações das massas populares, conduzidas por membros do clero, mediante a difusão de falsos milagres e de uma conduta moral vergonhosa. "Dos frades menores conventuais, que viajavam para coletar donativos, diz-se: 'Eles trapaceiam, roubam, fornicam e, quando não têm mais como ir adiante, fazem-se passar 
por santos a praticar milagres, exibindo um o hábito de São Vicente, outro o escrito de são Bernardino e um terceiro as rédeas do burro de Capistrano..." (BURCKHARDT, ibid, p. 332).

Identificada como causa de muitas paixões, a mulher do Renascimento italiano - ao menos da elite de certas regiões - desponta como "altamente culta e desenvolvida em sua individualidade", analisa Burckhardt (ibid, p. 318). Essa leitura se contradiz com uma das passagens de I Fioretti que reafirma a inferioridade da mulher. No Capítulo 33, Clara de Assis se recusa a benzer o pão a pedido do papa, o que confirma a postura de submissão da mulher da época. Diz a santa: "Santíssimo padre, perdoai-me, que eu seria digna de muita repreensão se diante do vigário de Cristo, eu, que sou uma vil mulherzinha, tivesse a presunção de dar tal bênção".

Por fim, consideramos que I Fioretti apresenta uma defesa apaixonada das clássicas verdades do cristianismo as quais, segundo a leitura de Burckhardt, estariam sujeitas a críticas, especialmente por conta da performance pouco convincente do clero tanto enquanto testemunho quanto por sua capacidade intelectual de argumentação. Uma das consequências desse quadro foi a proliferação de uma religiosidade individualista:

Diante da doutrina degenerada e tiranicamente imposta pela Igreja, era inevitável que a religião se transformasse novamente em um assunto concernente sobretudo ao indivíduo e a sua visão particular das coisas, comprovando, assim, que o espírito europeu estava vivo (BURCKHARD, 2009, p. 355).

Essa religiosidade subjetiva e individualista - que remonta ao antigo paganismo - parece ter exigido do clero um esforço maior no sentido de reafirmar os princípios da fé cristã, tais como, por exemplo, a concepção da Santíssima Trindade e a transubstanciação da Eucaristia. É o que podemos constatar na leitura de I Fioretti, respectivamente, nos capítulos 52 e 53. Especificamente no primeiro caso, diz o autor ao narrar episódios sobre a visão de Frei João do Alverne:

E então conheceu claramente como cada coisa criada representava o seu Criador, e como Deus está sobre e dentro e fora e ao lado de todas as coisas criadas. E conheceu depois um Deus em três pessoas e três pessoas em um Deus, e a infinita caridade a qual fez o filho de Deus se encarnar, por obediência ao Pai (I FIORETTI, Capítulo 52). 


\section{Considerações finais}

Ao relatar essas e outras passagens da vida de Francisco e de seus seguidores mais fiéis (por isso, considerados santos homens), arriscamos dizer que o autor de I Fioretti, mesmo se indiretamente, fala ao seu próprio contexto, a despeito da possível preocupação em registrar tais eventos para a posteridade, mais especificamente, para as novas gerações de membros da Ordem franciscana.

Trata-se, por assim dizer, de um discurso indireto, uma vez que o autor de I Fioretti não se reporta exatamente ao momento histórico em que escreve a obra. Porém, ao escolher e enfatizar certos argumentos que explicam e valorizam os eventos relatados, este parece estar preocupado em resgatar valores da Tradição cristã que, como sabemos por leituras como a de Jacob Burckhardt a respeito do Renascimento italiano, estão em confronto com as transformações culturais pelas quais passa a Europa - e, em especial, a Itália - nesse período, ao retomar valores culturais da Antiguidade clássica que se colocam, por vezes, na contramão de concepções cristãs sobre a vida, os costumes, a moral e a própria religião.

Assim, para além de comunicar ou testemunhar experiências e verdades cristãs, o autor de I Fioretti de San Francesco parece estar preocupado em resgatar antigas verdades da fé cristã, ampla e intensamente impostas pela Igreja durante toda a Idade Média. Trata-se, pois, de uma estratégia de importância indiscutível para a Igreja daquele momento, seja pela projeção das Ordens mendicantes (sobretudo a Franciscana) sobre as massas, seja porque esse tipo de relato hagiográfico - que tem no exemplo e na experiência um dos seus principais procedimentos argumentativos - possui um forte apelo sobre as consciências religiosas, já em crise desde o final do medievo. E, por isso, I Fioretti revela-se tanto um importante instrumento de comunicação do franciscanismo e do cristianismo quanto é um retrato de um contexto cujas paixões atestam o início de uma intensa transformação cultural na Europa do século XIV.

\section{Referências}

BALANCIN, Débora de Souza. As traduções brasileiras de I Fioretti de San Francesco: a leitura da obra no Brasil. Dissertação (Mestrado) - Universidade de São Paulo, São Paulo, 2008. 
BURCKHARDT, Jacob. A cultura do Renascimento na Itália: um ensaio. Tradução Sérgio Tellarioli. São Paulo: Companhia das Letras, 2009.

I FIORETTI DE SAN FRANCISCO. Disponível em: < http://www.paxetbonum.net/ fioretti_P.html >. Acesso em: 01 out. 2010.

MARQUES, Luís Henrique. As hagiografias como instrumentos de difusão do cristianismo católico junto aos meios rurais da Espanha visigótica. Tese (Doutorado) - Unesp, Assis, 2009.

MARQUES, Luís Henrique. Rede Vida de Televisão: análise da prática comunicacional da igreja católica a partir de um referencial. Dissertação (Mestrado) - Unesp, Bauru, 1999.

PAULA, Durval Saturnino Cardoso. Relações e reações do poder eclesiástico ao franciscanismo do século XIII e a eclesiologia militante de Leonardo Boff do século XX: um balanço historiográfico entre o medievo e a contemporaneidade. Revista Eletrônica de Ciências Sociais, Uberlândia, p. 8-18, set. 2010.

PEREIRA, Reginaldo de Oliveira; TORELLI, Leando Salman. História Moderna I. Batatais: Centro Universitário Claretiano, 2010. (Caderno de Referência de Conteúdo).

SANTOS, Eucleia Gonçalves. A Igreja Católica e a Ordem Franciscana. In: Em cima da mula, debaixo de Deus, na frente do inferno: os missionários franciscanos no sudoeste do Paraná (1903-1936). Curitiba: Universidade Federal do Paraná, 2005.

SCHMITT, Jean-Claude. Os vivos e os mortos na sociedade medieval. São Paulo: Companhia das Letras, 1999. 328p.

VAREZZE, Jacopo de. Legenda áurea. Tradução Hilário Franco Júnior. São Paulo: Companhia das Letras, 2003. 1056 p. 